\title{
PERANCANGAN ENTERPRISE ARCHITECTURE MENGGUNAKAN ZACHMAN PADA PT. SUTERA INDAH UTAMA
}

\author{
DESIGN ENTERPRISE ARCHITECTURE USING ZACHMAN IN \\ PT. SUTERA INDAH UTAMA \\ Agus Budiyantara $^{1 *}$, Jefry Leonardo ${ }^{2)}$ dan Johanes Fernandes Andry ${ }^{3)}$ \\ 1) Program Studi Teknik Informatika, STMIK Widuri, Jakarta \\ 2,3) Program Studi Sistem Informasi, Universitas Bunda Mulia, Jakarta
}

Diterima 14 Februari 2020 / Disetujui 24 Februari 2020

\begin{abstract}
PT. Sutera Indah Utama is a vertically integrated textile company, which supplies the domestic and international markets with high-quality knit fabrics and garments. PT. Sutera Indah Utama is integrated into professional home knitting, knitting coloring, procurement facilities along with supporting facilities, such as screen printing and embroidery. With an automatic hanging sewing system, using a modern product management system. Therefore the existing system in the company that requires very careful planning, so that it is planned according to the needs and needs within the company. Planning the entire company system that has had aspects of business and organization called Enterprise Architecture (EA). Which is used to improve the company's architecture by analyzing, documenting, and integrating architecture in a company? In order for a business process to reach one achieving work. As well as solving or solving a problem, to build an information system in the company in need of a Zachman Framework. Improving Information Systems (IS) and Information Technology (IT) can help and be efficient in supporting a business activity to achieve the goals and interests of the organization or company. The company's architecture in the company can achieve the desired goals optimally and in accordance with the company's business strategy.
\end{abstract}

Keywords: Zachman Framework, PT. Sutera Indah Utama, Information Sistem, Enterprise Architecture Planning

\begin{abstract}
ABSTRAK
PT. Sutera Indah Utama merupakan sebuah perusahaan tekstil yang terintegrasi secara vertikal, yang memasok pasar domestik dan internasional dengan kain rajut dan garmen berkualitas tinggi. PT. Sutera Indah Utama terintegrasi secara profesional rajutan in-house, pewarnaan rajut, fasilitas menjahit bersama dengan fasilitas pendukung, seperti sablon dan bordir. Dengan sistem jahit gantung secara otomatis sepenuhnya, menggunakan sistem manajemen produk modern. Oleh sebab itu sistem yang ada pada perusahaan memerlukan perencanaan yang sangat matang, agar terencana sesuai kepentingan dan kebutuhan di dalam perusahaan. Merencanakan seluruh sistem perusahaan yang di dalamnya mempunyai aspek bisnis dan organisasi yang di sebut dengan Enterprise Arsitektur (EA). Yang digunakan untuk merancang arsitektur perusahaan dengan menganalisis, mendokumentasikan, dan mengintergrasikan arsitektur di sebuah perusahaan. Agar proses bisnis mencapai salah satu kerangka kerja. Serta memecahkan atau menyelesaikan sebuah permasalahan, untuk membangun sebuah sistem informasi di perusahaan di butuhkan sebuah Zachman Framework. Sehingga Sistem Informasi (SI) dan Teknologi Informasi (TI) dapat semakin efektif dan efisien dalam mendukung sebuah kegiatan bisnis untuk mencapai sebuah tujuan dan kepentingan organisasi atau perusahaan. Dengan adanya sebuah Enterprise archititecture pada perusahaan, dapat dicapai sebuah tujuan yang di harapkan secara optimal dan sesuai strategi bisnis perusahaan.
\end{abstract}

Kata Kunci: Framework Zachman, PT. Sutera Indah Utama, Sistem informasi, Enterprise Architecture Planning

\footnotetext{
*Korespondensi Penulis :

E-mail: agusbudiyantara@yahoo.co.id
} 


\section{PENDAHULUAN}

Perkembangan pakaian dan rajutan menjadi kontribusi terbesar di perkembangan industri tekstil saat ini, pakaian dan rajutan menjadi salah satu kunci peningkatan dalam industri di bidang tekstil, yang menjadi salah satu penjualan terbesar di Indonesia dan dalam rangka pertumbuhan ekonomi di negara Indonesia baik Nasional maupun Internasional (Maga, dkk, 2016). Garment atau pakaian adalah produk akhir yang di lakukan pembuatan dengan secara pengabungan dan penjahitan serta potongan, hingga berupa menjadi bentuk pakaian dan busana yang di pakai oleh manusia setiap harinya (Rasyid, dkk, 2017). Pada dunia industri tekstil dan produk tekstil yang di hasilkan mempunyai daya sumbang yang tided kecil dalam ekspor untuk negara dan perekonomian negara (Kurpad, 2014). Sebagai bukti bahwa industri pakaian menjadi kontribusi terbesar di lihat dari tenaga kerja yang banyak (Haryono, dkk, 2018).

Dan membuktikan bahwa hampir rata-rata setiap minggu atau sebulan membuat atau memproduksi pakai dan motif yang berbeda-beda dan siap di pasarkan setiap minggu dan bulannya, hingga seiring trend yang berlangsung di Indonesia. Indutri pakaian dan rajutan menunjukan bahwa menguasai tekstil di Indonesia atau pun Internasional (Sa'idy, 2013). Selain itu industri pakaian dan rajutan memberikan kontribusi yang cukup besar untuk ekspor ke luar negeri, oleh karena itu perkembangan pakaian yang di pakai sehari-hari membuat industri tekstil semakin berkembang dan juga mempunyai brand-brand yang mempunyai nilai jual dan kualitas yang tinggi, sehingga orang-orang mempunyai daya tarik untuk membelinya (Umboh dan Timbel, 2018).
Pemerintah memprioritaskan tekstil karna mempunyai perkembangan yang cepat dan menjadikan industri yang bisa di unggulkan di Indonesia. Dalam pekembangan pakaian, pemerintah juga berharap industri tekstil dan pakaian, terus menjadi produk unggulan hingga mendapatkan nilai tinggi di bidang ekspor di bidang tekstil (Paradita dan Setyari, 2018). Penggunaan informasi teknologi di dalam perusahaan mampu menciptakan keunggulan dalam persaingan yang kompetitif dan juga menjadi sasaran utama dari upaya penerapan SI/TI di perusahaan. Pembangunan perancangan yang akan dilaksanakan dengan menggunakan strategi SI dan TI dapat mencapai target yang memuaskan. Bagi setiap perusahaan yang bergerak dalam bidang bisnis tentu mengharapkan keuntungan yang menjadi sebuah titik balik yang ingin dicapai (Saputra, 2015).

Penggunaan informasi teknologi dalam bisnis memudahkan setiap pelaku bisnis dan menciptakan efesiensi serta efektivitas bagi perusahaan sehingga dengan penggunaan informasi teknologi perusahaan mampu menciptakan keunggulan kompetitif dan mampu bersaing dalam pasar global, perkembangan organisasi yang semakin komplek mengakibatkan kebutuhan akan informasi dan data akan semakin meningkat (Tyas dan Tarmudji, 2013). Pada keunggulan perusahaan memebutuhkan sebuah peran Enterprise Architecture (EA), yang mempunyai sebuah hubungan dengan perancangan strategi bisnis dan pemanfaatan EA yang mempunyai gambaran sebuah organisasi ke arah tujuan pada bisnis yang berjalan dan implentasi (Zijl dan Vanbelle, 2014).

EA dikenal sebagai gambaran umum atau pedekatan pada bisnis dengan Sistem Informasi (SI) / Teknologi Informasi (TI) 
dalam sebuah organisasi. EA juga menghubungkan kesenjangan pada kegiatan yang di lakukan perusahaan dari strategi serta operasi, Sehingga lebih baik dalam menyelerasakan, megoptimalkan, menginergrasikan, dan semua yang berhubungan dengan organisasi (Besker, dkk, 2015).

Tujuan utama dari EA, untuk mencapai tujuan dan misi orgranisasi dengan mengurangi biaya sesuai dengan sistem SI/TI yang dilakukan dan menyelarasakan sistem dengan tujuan bisnis perusahaan, pada EA memiliki beberapa kerangka yaitu: TOGAF, Zachman Framework, dan Federal Enterprise Architecture. Kerangka kerja EA tersebut memiliki sebuah tujuan utama pada SI/TI dengan bisnis, namun setiap organisasi menggunaan kerangka kerja yang berbeda dalam menerapkan dan pengembangan pada SI/TI, hingga tujuan bisnis (Alshammari, 2017). Agar mencapai tujuan pada proses bisnis yang di terapkan sebelumnya, diperlukan sebuah strategi bisnis, untuk mengambil sebuah keputusan dalam suatu informasi perusahaan yang di kumpulkan dari data, penawaran, saran, rekomendasi serta baik kepentingan internal maupun eksternal untuk mengetahui keadaan pada perusahaan dan tujuan yang di inginkan serta mendapatkan hasil dan kebijakan sesuai rencana utama, serta menentukan rentang bisnis yang harus di kejar dan dikembangkan oleh perusahaan (Lendel, dkk, 2015).

Berdasarkan penjelasannya, PT. Sutera Indah Utama (SIU) memiliki Strategi bisnis yang membuat produksi pakaian semakin berkualitas, efektif dan kontrol kualitas yang baik. selain itu perusahaan harus menjaga dan memaksimalkan penggunaan peralatan produksi untuk membuat kualitas lebih baik. perusahaan masih memiliki masalah pada sistem produksi yaitu, sering terjadi kesalahan di perusahaan proses kerja, sering terjadi bahan hilang dalam persediaan, stok tidak sesuai dengan data yang keluar, analisis sistem yang kurang sehingga terjadiinya hasil produksi mengalami kecacatan dan laporan tidak cocok. Sehingga proses kerja menjadi terhambat, dan kurangnya koordinasi atau kontrol pada sistem, saat melakukan produksi. Di mana strategi bisnis dan SI/TI diperlukan, mereka berhasil diselaraskan, digunakan untuk menunjukkan bagaimana arsitektur perusahaan dapat memberikan kontribusi positif bagi penyelarasan perusahaan. oleh karena itu perusahaan memerlukan sebuah gambaran SI/TI agar sesuai dengan strategi bisnis. Berdasarkan penejelasan EA bahwa adanya berbagai kerangka kerja yang digunakan untuk mengambarkan semua SI/TI.

Dalam penelitian ini mengunakan sebuah kerangka kerja arsikteur Zachman Framework, sebagai kerangka kerja arsitektur yang digunakan untuk mengevaluasi, merancang dan serta membangun arsiktektur yang sesuai tujuan dari organisasi (Varga, 2013). Zachman Framework dapat menyelesaikan suatu masalah dengan menghasilkan sebuah perencanaan SI/TI sehingga dapat berjalan dengan efektif dan efisien, serta mendukung strategi bisnis dan tujuan perusahaan (Mani, dkk, 2015). Penelitian sebelumnya menggunakan Zachman dengan hasilnya adalah bahwa framework ini dapat mengimplementasikan SI/TI secara keseluruhan yang terkait dengan proses transaksi, pendaftaran dan logistik data, diharapkan perusahaan akan memperkerjakan beberapa pekerja yang memiliki keterampilan yang baik (Imbing dan Andry, 2019). 


\section{PENELITIAN YANG TERKAIT}

Setelah Merakit pakaian adalah proses yang sulit karena garis menjahit mengandung sejumlah operasi. Karenanya kapasitas kerja sering terjadi bervariasi dari orang ke orang. Langkah pertama untuk meningkatkan produktivitas dan kualitas adalah mengidentifikasi faktor-faktor yang memengaruhi dan dengan mengurangi ini dapat dengan mudah mencapai kualitas serta produksi di jalur jahit. Seperti yang kita tahu kondisi ekonomi berubah sangat cepat menjadi lebih penting untuk fokus pada investasi awal sebagai kompetisi tinggi di kawasan industri. Produktivitas dievaluasi dengan pencapaian menuju tujuan yang ditetapkan berdasarkan hubungan antara input dan output industri (Rajput, dkk, 2018).

Kinerja rencana operasional untuk meningkatkan efisiensi adalah dipahami oleh analisis Enterprise architecture (EA) dengan Zachman Framework, adalah salah satu alat yang efektif yang dapat membantu untuk pencegahan, identifikasi, pengendalian dan penghapusan kemungkinan kesalahan terjadi di industri Pakaian. Ini dapat diimplementasikan dengan mengumpulkan data dari industri pakaian jadi dan diimplementasikan. metode ini menunjukkan secara drastis mengurangi cacat produk, pengerjaan ulang, dan total biaya produksi di Indonesia industri garment (Sulaiman, 2018).

Industri pakaian dibagi menjadi beberapa proses dengan operasi yang berbeda. Operasi adalah salah satu langkahnya dalam urutan proses yang harus diselesaikan untuk mengubah bahan menjadi pakaian jadi seperti memotong, menjahit dan menyelesaikan pakaian, komponen atau gaya (Chandurkar, dkk, 2015). Pekerja terampil diperlukan untuk tingkat produksi yang tinggi. Produksi yang akurat metode dan proses, pelatihan dan pengawasan yang tepat sangat penting untuk mencapai peningkatan optimal pada produktivitas (Borse, dkk, 2016). Mengukuran kerja memudahkan pengguna untuk meningkatkan kinerja mereka selama operasi manufaktur. Setelah pengenalan Kebijakan Tekstil baru menghapus industri pakaian jadi dari kecil daftar skala industri, perubahan drastis ditemukan industri di pasar kompetitif.

Karena efisiensi dan produktivitas adalah alat yang kuat dalam meningkatkan daya saing perusahaan mana pun. Teknik Industri adalah faktor lain dalam industri garmen untuk meningkatkan sifat kerja dan metode kerja. Enterprise Architecture Planning merupakan metode yang digunakan untuk membangun sebuah arsitektur informasi yang dimana pendekatan perencanaan kualitas data yang berorientasi pada kebutuhan bisnis serta bagaimana cara implementasi dari arsitektur tersebut dilakukan sedemikian rupa dalam usaha untuk mendukung perputaran roda bisnis perusahaan dan pencapaian atau tujuan sistem informasi dan organisasi, dengan menerapkan metode ini proses bisnis perusahaan beroperasi secara efektif dan efisien, serta meningkat secara signifikan (Irfanto dan Andry, 2017).

\section{METODE PENELITIAN}

Dalam penelitian ini, langkahlangkah penelitian merujuk pada metodologi Enterprise Architecture (EA). EA memiliki komponen utama yang menunjukkan tahapan untuk menentukan dan merencanakan implementasi sistem informasi dan arsitektur teknologi. Langkah-langkah dalam penelitian ini dapat dilihat pada Gambar. 1 Metode Penelitian EA. 


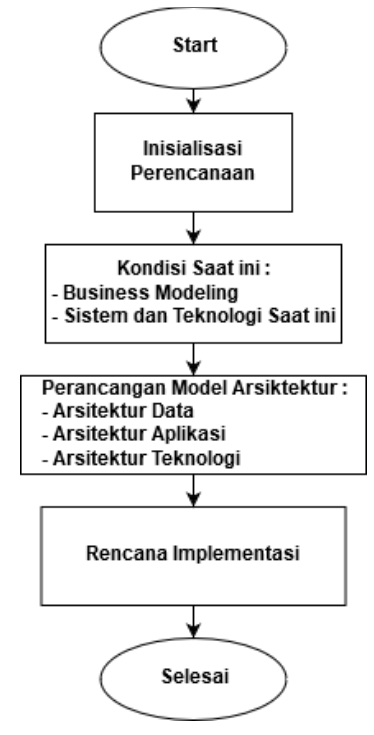

Gambar 1. Metode penelitian EA (Kristanto, 2017)

\section{A. Inisialisasi/Pe rencanaan}

Pada kegiatan ini meliputi studi pustaka yang berupa tentang pegayaan materi dalam perancangan Enterprise Architecture dan perancangan studi kasus arsitektur perusahaan yang di lakukan oleh orang lain sebelumnya serta menentukan arsitektur ruang lingkup, visi dan misi agar mencapai tujuan dari organisasi atau perusahaan, rencana dan komitmen dari pihak bersangkutan untuk merancang proses pengembangan ini.

\section{B. Pe modelan B is nis saat ini}

Pada proses ini mengumpul dan pengamatan dokomentasi dari struktur organisasi perusahaan, identifikasi fungsi bisnis, dan pembuatan model bisnis pemula atau awal.

\section{Sistem \& Teknologi}

Saat Ini, proses mengidentifikasi sistem dan teknologi yang saat ini berjalan dan menganalisis kondisi dalam organisasi.

\section{Analisis Kondisi Saat Ini}

Menganalisis kondisi perusahaan saat ini dengan menggunakan analisis SWOT (Strength, Weaknesses, Opportunities, and Threats) dan melihat kondisi kebutuhan perusahaan terhadap perubahan enterprise.

\section{Pe rancangan Arsitektur Data}

Pada kegiatan meneliti pendefinisian entitas data yang melibatkan di dalam organisasi lalu perancangan arsitektur data.

\section{Perancangan Arsitektur Aplikasi}

Pada kegiatan ini meliputi definisi proses yang terlibat dalam perusahaan atau organisasi dan perancangan arsitektur aplikasi atau proses.

\section{Perancangan Arsitektur Teknologi}

Pada kegiatan ini meliputi alur data dari proses yang terlibat di dalam perusahaan atau organisasi dan perancangan teknologi yang mendukung alur tersebut.

\section{Rencana Implementasi}

kegiatan ini disiapkan, sehingga kegiatan yang direncanakan dapat mencapai tujuan organisasi.tertentu

\section{HASIL DAN PEMBAHASAN}

\section{A. Inisialisasi perencanaan}

\section{Ruang Lingkup}

Pada penyusunan Enterprise Architecture Planning memiliki ruang lingkup PT. Sutera Indah Utama bergerak di bidang tekstil atau garment, dalam perusahaan memiliki proses produksi, penjualan dan penyimpanan. Dan PT. Sutera Indah Utama ingin memperbaiki kulitas produksi dan kulitas kontrol pada pemilihan bahan baku, agar hasil produksi yang di hasilkan mempunyai peningkatan pada kualitas produk menjadi lebih baik dan agar bisa lebih efisien. Dan tidak merugikan pihak perusahaan, serta dapat lebih unggul 
dari pesaing bisnis lainnya. PT. Sutera Indah Utama ingin mempunyai hasil yang baik dan unggul dari pesaing lainnya, baik dari Nasional hingga Internasional. Hingga membuat produk yang berkulitas dan berkerja sama dengan perusahaan lainnya, untuk memproduksi pakaian yang mempunyai kualitas yang baik dan mempertahankkan kepercayaan pada perusahaan yang berkerjasama.

\section{Tujuan}

a. Menjadi perusahaan tekstil/ garment yang terbaik di dunia dengan produk pakaian jadi yang terbaik dengan bahan berkualitas tinggi.

b. Meningkatkan pemasaran tekstil terutama dengan ekspor tekstil dan berusaha agar kinerja perusahaan perusahaan berada pada tingkat yang sehat untuk pencapaian laba yang sesuai dengan performa perusahaan dalam persaingan yang makin ketat dengan meluncurkan jenis produk yang spesifik kepasar Internasional.

c. Menghasilkan produk yang bermutu tinggi untuk meningkatkan kepuasan pelanggan,

d. Meningkatkan efisiensi di segala bidang untuk menghasilkan produk dengan harga yang kompetitif.

\section{Visi}

Menjadi perusahaan terbaik dalam bidang pemasaran dan distribusi tekstil yang memilki keunggulan dalam inovasi, mutu produk, dan kepuasan pelanggan.

\section{Metodologi Perencanaan Arsitektur}

a. Inisialsasi Perencanaan: Ruang lingkup dan sasaran, visi serta penentuan metodologi untuk perencanaan arsitektur sistem informasi Perusahaan. b. Pemodelan bisnis: Stuktur organisasi, model area fungsi bisnis dalam bentuk value chain dan hasil deskomposisi fungsi perusahaan.

c. Sistem Saat Ini \& Teknologi: Mengidentifikasi sistem dan teknologi saat ini dan menganalisi kondisi perusahaan.

d. Arsitektur Data: Tahap awal untuk membuat arsitektur enterprise, dengan pengertiannya tahap ini adalah pengumpulan data dan mendefinisikan entitas utama yang diketahui dari tahap pemodelan bisnis.

e. Arsitektur Aplikasi: Mengidentifikasi dan mendaftarkan aplikasi yang digunakan selama proses bisnis.

f. Arsitektur Teknologi: Mendefinisikan teknologi yang digunakan sesuai dengan aplikasi yang direncanakan.

\begin{tabular}{llr} 
g. Rencana & \multicolumn{2}{c}{ Implementasi: } \\
Merencanankan berbagai macam \\
arsitektur yang dirancang & sesuai \\
dengan kebutuhan dan tujuan & perusahaan.
\end{tabular}

\section{B. Business Modeling}

Pendefinisian area-area fungsi utama pada PT. Sutera Indah Utama menggunakan value chain, seperti yang di uruaikan pada Gambar. 2 Value Chain PT. Sutera Indah Utama Dalam gambar tersebut memiliki fungsi bisnis dikelompokan menjadi dua yaitu primary activities dan support activities.

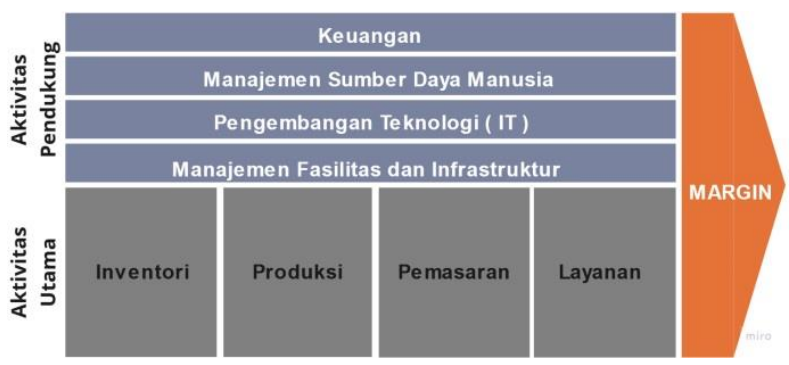

Gambar 2. Value Chain PT. Sute ra Indah Utama 
Pada organisasi perusahaan mempunyai tugas yang terkait dengan proses PT.Sutera Indah Utama. adapun proses bisnis yang di lakukan perusahaan sebagai berikut:

a. Keuangan: proses mengolahan keuangan perusahaan yaitu anggaran, pencarian anggaran, pengolahaan data, kegiatan yang dilakukan oleh perusahaan dan pelaporan keuangan.

b. Manajemen Sumber Daya Manusia: Menangani kegiatan perusahaan, pengelolaan karyawan baik gaji dan kinerja kerja, memdukung aktivitas perusahaan, dan implementasi sistem perencanaan.

c. Pengembangan Teknologi (IT): Proses kegiatan dalam rangka mengembangkan teknologi, perawatan, dan mendukung aktifitas perusahaan, serta menangani atau mengolah teknologi di dalam perusahaan.

d. Manajemen Fasilitas dan Infrastruktur: Mengelolah semua kebutuhan perusahaan dengan memberikan fasilitas pendukung, serta mendefinisikan kebutuhan dasar organisasi sistem stuktur yang di perlukan untuk kelancaran pada perusahaan.

e. Inventori: Mengelolah penyimpanan barang dan bahan, serta pengcekan stock yang ada di dalam gudang, dan pendataan barang dan bahan, baik masuk dan keluarnnya dari gudang.

f. Produksi: Mengelolah pembuatan pakaian yang sudah di rancang sesuai desain dan bahan dengan mengunakan mesin otomatis, serta tahap pengujian kualitas pada pakaian atau barang jadi, dan melakukan pengecekan serta pendata hasil produksi.

g. Pemasaran: Mengelohan penjualan produk atau pakaian, serta mendata permintaan pelanggan yang melakukan pemesanan pada produk atau pakaian.

h. Layanan: Memberikan informasi dan bantuan kepada pelanggan, serta melakukan penagihan pada pelanggan dan pengcekan tagihan.

\section{SWOT}

Berikut adalah hasil analisis SWOT, di terapkan pada Gambar 3. Hasil Analisa SWOT.

\begin{tabular}{|c|c|}
\hline Strengths & Weaknesses \\
\hline $\begin{array}{l}\text { - Mesin produksi berteknologi tinggi } \\
\text { Memenuhi permintaan pasar dengan } \\
\text { kualitas, desain, model dan motif } \\
\text { yang inovatif. } \\
\text { - Mempunyai kepercayaan oleh para } \\
\text { pelanggan dan produksi yang } \\
\text { meningkat. } \\
\text { Daya saing produk garment nasional } \\
\text { di pasaran internasional tergolong } \\
\text { tinggi. }\end{array}$ & $\begin{array}{l}\text { - Penggunaan sistem keluar masuknya } \\
\text { barang dan bahan masih kurang baik, dan } \\
\text { ketidak akuratan pada data inventori. } \\
\text { - Sistem pada perusahaan masih kurang } \\
\text { memadai dan sering terjadi kesalahan di } \\
\text { karnakan masih mengunakan microsoft } \\
\text { office, sehingga menyembabkan ketidak } \\
\text { akuratan pada data dan laporan. } \\
\text { - Sering terjadi keterlambatan produksi dan } \\
\text { sulit merencanakan produksi, dikarnakan } \\
\text { bahan yang tidak memcukupi. }\end{array}$ \\
\hline Opportunities & Threads \\
\hline $\begin{array}{l}\text { - Permintaan pasar dan produksi } \\
\text { semakin besar, baik dalam negeri dan } \\
\text { luar negeri. } \\
\text { - mempunyai potensi besar di bidang } \\
\text { ekspor. } \\
\text { - Proses produksi dilakuakan sesuai } \\
\text { jadwal, dan terencanakan. }\end{array}$ & $\begin{array}{l}\text { - Tuntunan pelanggan semakin tinggi. } \\
\text { Kualitas pengelolaan produksi } \\
\text { berpengaruh terhadap daya saing } \\
\text { perusahaan. } \\
\text { - Belum tercapai visi dan misi perusahaan, } \\
\text { apabila sistem perusahaan belum optimal. }\end{array}$ \\
\hline
\end{tabular}

\section{Gambar 3. Hasil Analisa SWOT}

\section{Sistem Saat Ini \& Teknologi}

Sistem yang sedang berjalan pada perusahaan, pada proses perusahaan sudah memiliki sistem yang tertruktur yaitu, dimulai dari proses pemasaran yang memiliki nilai jual pakaian pada pelanggan. Pelanggan memesan sebuah pakaian kepada markerting, dengan ketentuan jumlah, bahan, warna, model, ukuran pada masing-masing pakaian, setelah itu masuk ke dalam proses desain dengan mengikuti kententuan data yang sudah di berikan oleh bagian pemasaran, dari proses desain dilanjutkan oleh proses produksi untuk pembuat pakaian sesuai design yang sudah di tentukan sebelumnya, di proses produksi adalah proses pembuatan pakaian, sebelum melakukan produksi bagian produksi meminta bahan pada bagian inventori, bagian inventori menyediakan bahan dan mengirim bahan ke bagian produksi, lalu di lanjutkan proses pembuatan pakaian, pada proses produksi juga memiliki status produksi yang memberitahukan bahwa 
proses pembuatan selesai atau dalam pengerjaaan, setelah proses produksi pakaian selesai, lalu bagian melakukan pengecekan pada pakaian, lalu dari hasil yang sudah teruji, bagian produksi mengirim pakaian ke inventori untuk di simpan, dari bagian menginput pakaian yang masuk ke dalam inventori barang, dan melakukan pengemasan untuk di kirim ke customer atau toko serta menginput barang keluar. jika di inventori bahan untuk produksi dalam keadaan kosong atau kurang, bagian inventori akan memesan bahan ke bagian penyediaan, serta memberikan laporan pemesanan ke bagian keuangan, setelah memesanan berhasil, pihak penyediaan mengirim barang ke pabrik, bagian inventori penginput bahan masuk ke dalam inventori.

Teknologi yang sedang berjalan pada perusahaan yaitu di mulai, dari komputer dan microsoft office untuk keperluan perusahaan untuk membuat laporan, keuangan, data karyawan, gaji karyawan, desain dan mendukung aktivitas perusahaan untuk kebutuhan proses atau tujuan perusahaan, pada perusahaan mengunakan teknologi cctv untuk memantau aktivitas-aktivitas, yang di lakukan pada perusahaan dan juga sebagai teknologi keamanan di dalam perusahaan.

\begin{tabular}{|l|l|l|l|l|l|}
\hline \multicolumn{1}{|c|}{ Devisi } & $\begin{array}{c}\text { Penyimpanan } \\
\text { Data }\end{array}$ & $\begin{array}{c}\text { Sistem } \\
\text { Operasi }\end{array}$ & $\begin{array}{c}\text { Perangkat } \\
\text { Lunak }\end{array}$ & $\begin{array}{c}\text { Perangkat } \\
\text { Pendukung }\end{array}$ & $\begin{array}{c}\text { Perangkat } \\
\text { Komunikasi }\end{array}$ \\
\hline Inventory & $\begin{array}{l}\text { HDD internal } \\
\text { dan eksternal }\end{array}$ & Windows 7 & Microsoft Office & Printer, Fax & LAN \\
\hline Produksi & $\begin{array}{l}\text { HDD internal } \\
\text { dan eksternal }\end{array}$ & Windows 7 & $\begin{array}{l}\text { Microsoft } \\
\text { Office, Aplikasi } \\
\text { Desain }\end{array}$ & Printer, Fax & LAN \\
\hline Pemasaran & $\begin{array}{l}\text { HDD internal } \\
\text { dan eksternal }\end{array}$ & Windows 7 & Microsoft Office & Printer, Fax & LAN \\
\hline Keuangan & $\begin{array}{l}\text { HDD internal } \\
\text { dan eksternal }\end{array}$ & Windows 7 & Microsoft Office & $\begin{array}{l}\text { Printer, Fax, } \\
\text { Scanner }\end{array}$ & LAN \\
\hline $\begin{array}{l}\text { Manajemen } \\
\text { Sumber Daya } \\
\text { Manusia }\end{array}$ & $\begin{array}{l}\text { HDD internal } \\
\text { dan eksternal }\end{array}$ & Windows 7 & Microsoft Office & $\begin{array}{l}\text { Printer, Fax, } \\
\text { Scanner }\end{array}$ & LAN \\
\hline Layanan & $\begin{array}{l}\text { HDD internal } \\
\text { dan eksternal }\end{array}$ & Windows 7 & Microsoft Office & $\begin{array}{l}\text { Printer, Fax, } \\
\text { Scanner }\end{array}$ & LAN \\
\hline
\end{tabular}

\section{Gambar 4. Kondisi Sistem Dan Teknologi} PT. Sutera Indah Utama

Pada teknologi pembuatan pakaian atau produksi, mengunakan sebuah mesin otomatis yang di kendalikan untuk melakukan proses produksi, yaitu 10 unit mesin embriodery / 20 kepala (Barudan), 1 unit Mesin Cetak Layar Otomatis (Penantang), 8 Lines Hanging System, 7 Lines Normal System dengan jumlah mesin sekitar 700 unit. Berikut adalah hasil kondisi sistem dan teknologi perusahaan, pada Gambar 4. Kondisi Sistem Dan Teknologi PT. Sutera Indah Utama.

\section{Analisa Hasil Kondisi Saat ini}

Hasil Analisis SWOT (Table 1) dan value chain, proses bisnis PT. Sutera Indah Utama memiliki banyak kelemahan, dan adanya ancaman. Pada sistem yang digunakan perusahaan belum optimal, dari hasil kondisi enterprise yang digunakan oleh perusahaan, di rencanakan proses bisnis terintergrasi dalam teknologi yang di gunakan untuk pendokumentasian, berikut adalah hasil analisa ditunjukan pada Gambar 5. Kebutuhan data.

\begin{tabular}{|l|l|l|l|}
\hline No. & Entitas Data & No. & Entitas Data \\
\hline 1 & Barang \& Bahan Masuk & 15 & Anggaran \\
2 & Barang \& Bahan Keluar & 16 & Pencairan Anggaran \\
3 & Stock Barang \& Bahan & 17 & Kegiatan perusahaan \\
4 & Laporan Inventori & 18 & Laporan Keuangan \\
5 & Purchase Order & 19 & Surat Menyurat \\
6 & Bahan Permintaan & 20 & Gaji Karyawan \\
7 & Status Produksi & 21 & Kinerja Karyawan \\
8 & Laporan Produksi & 22 & Aset \\
9 & Permintaan Produksi & 23 & Penagihan \\
10 & Proses Produksi & 24 & Informasi \\
11 & Permintaan Pelanggan & 25 & Laporan Layanan \\
12 & Penjualan Produk & 26 & Penyimpanan \\
13 & Laporan Penjualan & 27 & Pendataan Karyawan \\
14 & Pendataan Pelanggan & & \\
& \multicolumn{3}{|l}{} \\
\hline
\end{tabular}

\section{Gambar 5. Kebutuhan data}

Ada enam Proses yang di rencanakan Dalam Proses Bisnis yaitu:

1. Pengolahaan Inventori: Proses Pengolahan Inventori, memiliki proses penginputan barang dan bahan masuk maupun keluar, pengecekan pada stock barang dan bahan, pengcekan permintaan bahan yang di minta oleh pihak produksi, melakukan purchase order, dan mempunyai laporan dari proses pengolahan inventori. 
2. Pengolahaan Produksi: Proses Pengolahan Produksi, memiliki proses permintaan bahan untuk produksi pakaian, mempunyai status produksi yang sedang di proses, pengcekan permintaan produksi dan mempunyai laporan dari proses pengolahaan produksi.

3. Pengolahaan Pemasaran: Proses Pengolahaan Pemasaran, memiliki proses menginput permintaan dari pelanggan sesuai keinginan dan mendata indetitas pelangan, penjualan produk atau pakaian, dan mempunyai laporan dari proses pengolahan Pemasaran atau penjualan.

4. Pengolahaan Keuangan: Proses pengolahaan keuangan, memiliki proses perencanaan atau penganggaran, pemeriksaan dan pengelolaan, pencairan dana, dan kegiatan yang di lakukan oleh perusahaan, dan mempunyai laporan pengolahaan keuangan.

5. Pengolahaan Sumber Daya Manusia: Proses pengolahaan Sumber Daya Manusia, Memiliki proses pendataaan karyawan baru, pengcekan kinerja karyawan dan gaji karyawan, surat menyurat dan mengolah aset Perusahaan.

6. Pengolahaan Layanan: Proses Pengolahaan Layanan, Memiliki proses pengcekan tanggihan, hingga penangihan, memberikan informasi atau bantuan, serta mempunyai laporan Layanan.

\section{Arsitektur data}

Arsitektur data dilakukan berdasarkan pertimbangan kebutuhan data (Tabel 3) dari setiap proses, dan memiliki relasi dari seluruh proses, berikut adalah rancangan teknologi dan prioritas di tunjukan pada Tabel 1. Rancangan Teknologi, Tabel 2. Prioritas Teknologi.
Tabel 1. Rancangan Teknologi

\begin{tabular}{|c|l|c|}
\hline No. & $\begin{array}{c}\text { Perencanaan } \\
\text { Aplikasi }\end{array}$ & Pengguna \\
\hline 1 & Inventori & Admin Gudang \\
\hline 2 & Produksi & Admin Produksi \\
\hline 3 & Pemasaran & Markerting \\
\hline 4 & Keuangan & Akuntansi \\
\hline 5 & $\begin{array}{l}\text { Manajemen } \\
\text { Sumber Daya } \\
\text { Manusia }\end{array}$ & HRD \\
\hline 6 & Layanan & Customer Service \\
\hline
\end{tabular}

Tabel 2. Prioritas Teknologi

\begin{tabular}{|c|l|c|}
\hline No. & \multicolumn{1}{|c|}{$\begin{array}{c}\text { Perencanaan } \\
\text { Aplikasi }\end{array}$} & Prioritas \\
\hline 1 & Inventori & Tinggi \\
\hline 2 & Produksi & Tinggi \\
\hline 3 & Pemasaran & Sedang \\
\hline 4 & Keuangan & Sedang \\
\hline 5 & $\begin{array}{l}\text { Manajemen } \\
\text { Sumber Daya } \\
\text { Manusia }\end{array}$ & Sedang \\
\hline 6 & Layanan & Rendah \\
\hline
\end{tabular}

\section{E. Arsitektur Aplikasi}

Tahap ini bertujuan untuk mengidentifikasi aplikasi-aplikasi yang di perlukan untuk mengelola data dan mendukung bisnis, di terapkan pada Tabel 3. Rekomendasi Aplikasi.

\section{Tabel 3. Rekomendasi Aplikasi}

\begin{tabular}{|l|l|}
\hline $\begin{array}{l}\text { Kandidat } \\
\text { Aplikasi }\end{array}$ & Deskripsi Aplikasi \\
\hline Inventori & $\begin{array}{l}\text { Sistem yang mengelola } \\
\text { adminisasi pergudangan, } \\
\text { persedian barang dan bahan,dan } \\
\text { laporan barang dan bahan. }\end{array}$ \\
\hline Produksi & $\begin{array}{l}\text { Sistem yang mengelola } \\
\text { produksi, dari status produksi, } \\
\text { permintaan bahan, permintaan } \\
\text { produksi dan laporan produksi. }\end{array}$ \\
\hline Pemasaran & $\begin{array}{l}\text { Sistem yang menangani untuk } \\
\text { penjualan produk, dan mendata } \\
\text { pelanggan, serat permintaan } \\
\text { pelanggan. }\end{array}$ \\
\hline Keuangan & $\begin{array}{l}\text { Menangani segala seseuatu yang } \\
\text { berkaitan dengan keuangan dan }\end{array}$ \\
\hline
\end{tabular}




\begin{tabular}{|l|l|}
\hline & $\begin{array}{l}\text { proses pembuatan laporan dan } \\
\text { neraca keuangan. }\end{array}$ \\
\hline Manajemen & Sistem yang mengelola sumber \\
Sumber & daya manusia, yaitu pendataan \\
Daya & karyawan, informasi karyawan, \\
Manusia & $\begin{array}{l}\text { surat menyurat, dan kebutuhan } \\
\text { perusahaan. }\end{array}$ \\
\hline Layanan & $\begin{array}{l}\text { Sistem layanan yang menangani } \\
\text { pelanggan, baik informasi atau } \\
\text { pun bantuan dan penagihan. }\end{array}$ \\
\hline
\end{tabular}

\section{F. Portofolio Aplikasi}

\section{Tabel 4. Hasil Portofolio Aplikasi}

\begin{tabular}{|c|c|}
\hline Strategic & High Potential \\
\hline $\begin{array}{ll}\text { 1. } & \text { Sistem } \\
\text { Informasi } \\
\text { Produksi } \\
\text { 2. Sistem } \\
\text { Informasi } \\
\text { Pemasaran } \\
\end{array}$ & $\begin{array}{l}\text { 1. Sistem Informasi } \\
\text { Inventori }\end{array}$ \\
\hline Key Operational & Support \\
\hline $\begin{array}{ll}\text { 1. } & \text { Sistem } \\
\text { Informasi } \\
\text { Keuangan } \\
\text { 2. Sistem } \\
\text { Informasi } \\
\text { Sumber Daya } \\
\text { Manusia }\end{array}$ & $\begin{array}{l}\text { 1. Sistem Informasi } \\
\text { Layanan }\end{array}$ \\
\hline
\end{tabular}

Pertimbangan kelayakan terhadap hasil dari blueprint arsitektur yang di rencanakan, dilihat pada Tabel 3 berdasarkan evaluasi perencanaan implementasi sistem kepada pimpinan PT. Sutera Indah Utama. dari hasil evalusi blueprint berpegaruh pada proses perusahaan, dan dapat di terealisasi dengan baik untuk masa depan. berikut pengelompokan arsitektur aplikasi, pada Tabel 4. Hasil Portofolio Aplikasi.

\section{G. Arsitektur Teknologi}

Tujuan dari tahapan ini adalah menentukan strategi distribusi aplikasi dan data serta mendefinisikan platform teknologi yang akan menjadi lingkungan bagi aplikasi dan data mendukung fungsi bisnis seperti pada Gambar. 6 Jaringan Perusahaan.

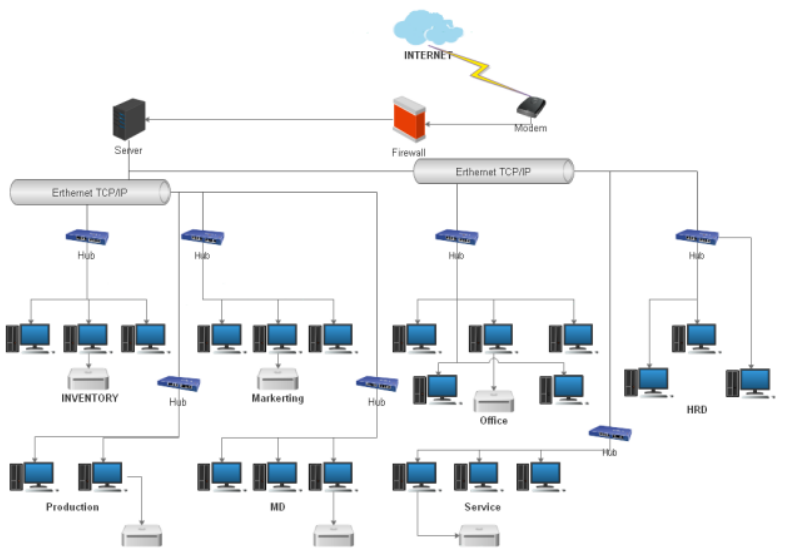

Gambar 6. Jaringan Perusahaan

Relasi Platform Teknologi Dengan Aplikasi

\begin{tabular}{|c|c|c|c|c|c|c|c|}
\hline \multirow[b]{3}{*}{ 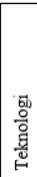 } & & \multicolumn{4}{|c|}{ Perangkat Lunak } & \multirow{2}{*}{$\begin{array}{l}\text { Jaringan } \\
\text { Jaringan \& } \\
\text { Perangkat }\end{array}$} & \multirow{2}{*}{$\begin{array}{l}\text { Media } \\
\text { Platform }\end{array}$} \\
\hline & & \multicolumn{2}{|c|}{$\begin{array}{l}\text { Sistem } \\
\text { Operasi }\end{array}$} & \multirow{2}{*}{ 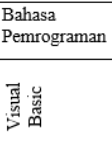 } & \multirow{2}{*}{ 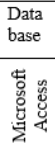 } & & \\
\hline & & 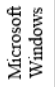 & 罩 & & & $\begin{array}{l}\text { 堨 } \\
\text { 首 }\end{array}$ & ¿ \\
\hline \multirow{6}{*}{ 丵 } & Inventori & $\checkmark$ & $\checkmark$ & $\checkmark$ & $\checkmark$ & $\checkmark$ & $\checkmark$ \\
\hline & Produksi & $\checkmark$ & $\checkmark$ & $\checkmark$ & $\checkmark$ & $\checkmark$ & $\checkmark$ \\
\hline & Pemasaran & $\checkmark$ & $\checkmark$ & $\checkmark$ & $\checkmark$ & $\checkmark$ & $\checkmark$ \\
\hline & Keuangan & $\checkmark$ & $\checkmark$ & $\checkmark$ & $\checkmark$ & $\checkmark$ & $\checkmark$ \\
\hline & $\begin{array}{l}\text { Manajemen Sumber } \\
\text { Daya Manusia }\end{array}$ & $\checkmark$ & $\checkmark$ & $\checkmark$ & $\checkmark$ & $\checkmark$ & $\checkmark$ \\
\hline & Layanan & $\checkmark$ & $\checkmark$ & $\checkmark$ & $\checkmark$ & $\checkmark$ & $\checkmark$ \\
\hline
\end{tabular}

\section{Gambar 7. Hubungan Platform Teknologi Dengan Aplikasi}

Tahapan ini dimaksudkan untuk melakukan justifikasi bagi platform teknologi dengan cara merelasikannya dengan aplikasi yang terdefinisi dengan arsitektur aplikasi yang memerlukan teknologi, berikut pada Gambar 7. Hubungan Platform Teknologi dengan Aplikasi. 


\begin{tabular}{|l|l|l|c|}
\hline $\begin{array}{c}\text { Rencana } \\
\text { Arsitektur }\end{array}$ & \multicolumn{1}{|c|}{ Dampak Positif } & \multicolumn{1}{|c|}{ Dampak Negatif } & Waktu Perngerjaan \\
\hline Data & $\begin{array}{l}\text { Menghubungkan data } \\
\text { platform dan aplikasi dari } \\
\text { jarak dekat ataupun jarak } \\
\text { jauh }\end{array}$ & $\begin{array}{l}\text { Membutuhkan biaya besar } \\
\text { dalam membuat basis data }\end{array}$ & 1 - 2 Bulan \\
\hline Aplikasi & $\begin{array}{l}\text { Pelaksanaan aktifivitas } \\
\text { perusahaan lebih efektif } \\
\text { dan efesien, serta } \\
\text { memudahkan setiap } \\
\text { proses yang berjalan di } \\
\text { dalam perusahaan }\end{array}$ & $\begin{array}{l}\text { Membutuh waktu lama pada } \\
\text { tahap implementasi sistem yang } \\
\text { dibangun dan penyesuaian } \\
\text { aplikasi }\end{array}$ & 6 - 8 Bulan \\
\hline Teknologi & $\begin{array}{l}\text { Menghubungkan setiap } \\
\text { jaringan komputer pada } \\
\text { perusahaan sehingga } \\
\text { sistem yang berjalan } \\
\text { menjadi lebih efektif dan } \\
\text { efisien }\end{array}$ & $\begin{array}{l}\text { Membutuhkan waktu lama dan } \\
\text { biaya yang besar dalam } \\
\text { membangun jaringan komputer }\end{array}$ & $3-4$ Bulan \\
\hline $\begin{array}{l}\text { Proses } \\
\text { Bisnis }\end{array}$ & $\begin{array}{l}\text { Prosedur sudah } \\
\text { direncanakan dengan } \\
\text { baik, sehingga dapat } \\
\text { meminimalkan resiko } \\
\text { pada sistem perusahaan. }\end{array}$ & $\begin{array}{l}\text { Membutuhkan waktu lama } \\
\text { dalam perencanaan proses bisnis } \\
\text { yang akan berjalan nanti nya. }\end{array}$ & $3-4$ Bulan \\
\hline
\end{tabular}

\section{Gambar 8. Pertimbangan Blueprint Arsitektur}

\section{H. Rencana Implementasi}

Pada rencana implementasi di lakukan tahapan yaitu pada Gambar 8. Pertimbangan Blueprint Arsitektur.

\section{KESIMPULAN DAN SARAN}

\section{A. Kesimpulan}

Kesimpulan dari hasil dan pembahasan yang telah di laukan mengunakan metode Zachman Framework, disimpulkan sebagai berikut:

1. Enterprise architecture di butuhkan agar perusahaan memiliki arsitektur informasi yang baik dan baku serta dapat disajikan sebagai dasar pengembangan sistem informasi bagi perusahaan.

2. Manfaat enterprise architecture bagi perusahaan tekstil ini adalah sebagai landasan pengembangan sistem infomasi perusahaan, agar pengembangan yang di lakukan sesuai dari visi, misi dan tujuan dari PT. Sutera Indah Utama.

3. Zachman framework arsitektur enterprise menyediakan cara untuk memandang dan mendifinisikan sebuah enterprise secara formal dan testuktur, untuk ketersediaan dokumentasi data pada sistem informasi dan teknologi informasi yang mendukung sebuah proses bisnis perusahaan dengan pengembangan teknologi.

4. Arsitektur informasi enterprise akan menjadi keuntungan dalam investasi teknologi yang mempunyai jangka panjang dengan pertimbangan dan mengurangi sebuah redudansi data, sehingga proses bisnis perusahaan sesuai kepentingan dan tujuan.

\section{B. Saran}

Saran agar proses bisnis di PT. Sutera Indah Utama berjalan dengan lancar dan sesuai tujuan pada perusahaan yang berjalan, yakni sebagai berikut:

1. Dengan adanya arsitektur enterprise pada perusahaan, agar strategi dan perencanaan, berjalan dengan lancar dan pengembangan sistem yang di rancangan secara matang sesuai kebutuhan dan penyajian dokumentasi untuk mengetahui perencanaan kedepannya.

2. Model enterprise architecture yang telah di hasilkan di PT. Sutera Indah Utama dapat menjadikan kunci kesuksesan bisnis, dan untuk meningkatkan strategi proses bisnis, baik sekarang masa yang akan datang.

3. Zachman Framework adalah framework arsitektur enterprise yang mempunyai cara pandang dalam menjalankan proses bisnis dan mendefinisikan enterprise sercara tersuktur sesuai proses bisnis dan tujuan serta ketersedian dokumentasi pada data, sistem hingga teknologi yang sangat mendukung proses bisnis yang berjalan dan pengembangan pada teknologi informasi.

\section{DAFTAR PUSTAKA}

Alshammari, B. M. 2017. Enterprise Architecture Frameworks: A Critique Review from a Security Perspective. Int. J. Comput. Appl., vol. 174, no. 5, pp. 975-8887.

Besker, T., Olsson, R., dan Pessi, K. 2015. The Enterprise Architect profession: An empirical study. Ecime, no. September 2015, p. 8.

Borse, S. Shrinivasan, V., dan Shivankar, V. 2016. Improving the Garment 
Productivity by Using New Designs of Folder. Int. J. Text. Eng. Process., vol. 2, no. May, pp. 61-65.

Chandurkar, P., Kakde, M., dan Bhadane, A. 2015. International Journal on Textile Engineering and Processes, ISSN : 2395-3578 Improve the Productivity with help of Industrial Engineering Techniques," no. November.

Haryono, T., Khoiriyah, S., Handayani, R.,dan Sugiarti, R. 2018. Mengapa UKM Garmen Di Kabupaten Klaten Mampu Bertahan Di Tengah Persaingan Pasar Bebas?. EKUITAS (Jurnal Ekon. dan Keuangan), vol. 1, no. 4 , p. 552.

Imbing, B., andry, J. F. 2019. Enterprise Architecture Planning For Cantata Music School Institute Using Zachman. Journal Of Systems Integration. Vol. 3, hal. 22-30, 2019.

Irfanto, R. dan Andry, J. F. 2017. Perancangan Enterprise Architecture Menggunakan Zachman Framework (Studi Kasus: PT.Vivamas Adipratama). Seminar Nasional Sains dan Teknologi 2017, Fakultas Teknik Universitas Muhammadiyah Jakarta, 1-2 November 2017, pp. 1-9.

Lendel, V., Hittmár, S., dan Latka, M. 2015. Application of Management of Innovation Processes in Enterprises: Management Approach, Problems and Recommendations. Procedia Econ. Financ., vol. 34, no. 15, pp. 410-416.

Kristanto, T. 2017. Enterprise Architecture Planning Untuk Proses Pengelolaan Manajemen Aset Dengan Zachman Framework. Regist. J. Ilm. Teknol. Sist. Inf., vol. 2, no. 2, p. 98.

Kurpad, M. R. 2014. Article information:," J. Int. Trade Law Policy, vol. 13, no. 1, pp. 80-96.

Maga, Y. L. V., Tommy, P. dan Tulung, J.E. 2016. Analisis Struktur Modal, Profitabilitas Dan Struktur Aktiva Terhadap Nilai Saham Pada Perusahaan Tekstil Dan Garmen Yang
Terdaftar Di Bursa Efek Indonesia (BEI) Periode 2011-2014," Jurnal EMBA, vol. 4, no. 3, pp. pp. 411-422.

Mani, M., Uludag, S., dan Zolinski, C. 2015. On Evaluating the Use of Zachman Framework in Computer Science and Information Systems Classes," J. Comput. Sci. Coll., no. August.

Paradita B. A. dan Setyari, N.P.W. 2018. Analisis Determinan Perkembangan Ekspor Tekstil Dan Produk Tekstil Indonesia. E-Jurnal EP Unud, vol. Vol. 7 No.4, pp. 806-839.

Rasyid, M., Surachman, S., dan Sugiono, S. 2017. Analisis Perbaikan Work Station Pada Proses Produksi Garment Dengan Menggunakan Pendekatan Environment Ergonomic. J. Eng. Manag. Industial Syst., vol. 4, no. 2, pp. 121-129.

Rajput, D., Kakde, M., Chandurkar, P., dan Raichurkar, P. P. 2018. Enhancing Efficiency and Productivity of Garment Industry by Using Different Techniques Enhancing Efficiency and Productivity of Garment Industry by Using Different Techniques.

Tyas. T. S., dan Tarmuji, A. 2013. Perancangan Enterprise Architecture Planning (EAP) Pada Proses Manajemen Aset Dengan Zachman Framework. J. Sarj. Tek. Inform., vol. 1, pp. 97-110.

Sa'idy, I. B. 2013. Dekomposisi Pertumbuhan Ekspor Tekstil dan Produk Tekstil Indonesia ke Amerika Serikat. JEJAK (Jurnal Ekon. dan Kebijakan), vol. 6, no. 1, pp. 10-16.

Saputra, D. 2015. Perancangan Enterprise Architecture Zachman Framework Untuk Jasa Layanan Pasang Baru Dan Tambah Daya Listrik Pada Perusahaan Jasa Listrik Swasta. J. Khatulistiwa Inform., vol. 3, no. 1.

Sulaiman, R. 2018. Perancangan Strategis Perencanaan Sistem Informasi Menggunakan Zachman Framework 
dari Segi Planner. J. Sisfokom (Sistem Inf. dan Komputer), vol. 5, no. 1, p. 60.

Umboh, D. S. O., dan Tumbel, A. 2015. Towards Purchasing," Anal. Kualitas Produk, Brand Image Dan Life Style Terhadap Keputusan Pembelian Pakaian Wan. Di Mississippi Manad. T. Sq., vol. 3, no. 1, pp. 1096-1105.

Varga, M. 2013. Zachman framework in teaching information systems," Proc. Int. Conf. Inf. Technol. Interfaces, ITI, no. July, pp. 161-166.

Zijl, C. V. dan Van Belle, J. P. 2014.

Organisational Impact of Enterprise Architecture and Business Process Capability in South African Organisations. Int. J. Trade, Econ. Financ., vol. 5, no. 5, pp. 405-413. 